\title{
EL LADO OSCURO DE LA NACIÓN ¿SE PUEDE DESCOLONIZAR LA IDENTIDAD ESPAÑOLA?
}

The dark side of the nation. Can Spanish identity be decolonized?

\author{
ROBERTO GIL HERNÁNDEZ \\ UNIVERSIDAD DE LA LAGUNA (ESPAÑA) \\ rgilhern@ull.edu.es http://orcid.org/0000-0003-4905-6550
}

\section{RECIBIDO: 24 DE AGOSTO DE 2018 ACEPTADO: 25 DE FEBRERO DE 2019}

RESUMEN: La identidad española no solo implica la definición de lo que somos, sino también de lo que nos falta, de todo aquello que sus narrativas autorizadas han obviado de forma recurrente. La finalidad de este deliberado ejercicio totalizador ha sido siempre la misma: reproducir la hegemonía de sus élites dirigentes. Así ha sucedido desde el inicio de la expansión atlántica protagonizada por el imperio colonial hispano, durante la articulación pionera del país conforme al programa liberal, con su primera gran crisis y resurrección nacionalista, y en el momento actual de normalización democrática neoliberal. En este artículo, voy a tratar de constatar la existencia de dicha exclusión en torno a estas cuatro oleadas de construcción identitaria que ya suman seis siglos, explicitando la necesidad de analizar este proceso mediante la crítica establecida por el pensamiento descolonial, el postestructuralismo y el psicoanálisis lacaniano.

PALABRAS CLAVE: colonialidad, modernidad, nacionalismo, pensamiento descolonial, psicoanálisis.

ABSTRACT: The Spanish identity not only implies the definition of what We are, but also of what We lack, the part obviated by its authoritative narratives recurrently. The purpose of this deliberate totalization exercise has always been the same: to reproduce the hegemony of its ruling elites. This has happened since the beginning of the Atlantic expansion of the Spanish colonial empire, during the pioneer articulation of the country according to the liberal program, with its first great crisis and nationalist resurrection, and also at the present moment of neoliberal democratic normalization. In this article, I will try to verify the existence of this exclusion around these four waves of identity construction in the last six centuries, explaining the need to analyze this process through the criticism established by the Decolonial Thought, Post-structuralist Theories and Lacanian Psychoanalysis.

KEY WORDS: coloniality, modernity, nationalism, decolonial thinking, psychoanalysis. 
España no tiene esencia. Ninguna nación la tiene, y España menos. Y el error filosófico se complica en el error político cuando, al buscarle una esencia, que por serlo había de resultar totalmente representativa, se eligen los caracteres de una parte sola.

Eduardo Nicol. La vocación bumana

A lo largo de los siglos que componen la historia moderna de España puede constatarse la 'existencia' de, al menos, cuatro momentos cruciales en la formulación de su identidad. Me refiero, partiendo del planteamiento original de Susan Martin-Márquez, al desarrollo de una serie de "oleadas de construcción nacional" (2011: 27) en las que sus principales dispositivos de saber y del ser han registrado un dinamismo inaudito para esclarecer cuanto constituye, pero también cuanto queda al margen de lo español.

Sin esta espaciada representación temporal de tales ansias de completitud, resultaría imposible explicitar la trayectoria histórica que ha descrito el país, así como sus herencias en el enorme espacio geográfico en que se ha forjado su conciencia colectiva. Por eso, en las páginas que siguen intentaré delimitar el alcance de las cuatro fases de exaltación que, en mi opinión, han marcado la deriva identitaria de España desde sus primeras enunciaciones, hace ya más de seis siglos, hasta la actualidad, cuestionando en todo momento las pretensiones totalizadoras que esta ha representado a nivel simbólico y afectivo.

Para lograrlo, además de recurrir al pensamiento descolonial, me valdré de conceptos provenientes del postestructuralismo y, sobre todo, del psicoanálisis lacaniano, con el fin de "encontrar una salida de los puntos muertos a que han llegado" los estudios sobre la identidad bajo "los enfoques marxistas clásicos, especulativos y analíticos" (Robinson en Stavrakakis, 2010: 17). En otras palabras, trataré de subrayar el carácter constitutivo de determinados elementos latentes o excluidos del autorretrato nacional español, entendido aquí como una trama significante cuyas pulsiones también son útiles para desvelar la naturaleza contingente de toda identidad, sobre todo cuando esta es planteada como un imperativo universal. Todo ello con el objetivo declarado de señalar, aunque solo sea de manera indiciaria, cuanto ha encubierto su condición moderna y posmoderna, así como sus turbadores vínculos con la colonialidad.

\section{PRIMERA OLEADA: EL DISCURSO DE LA PUREZA DE SANGRE}

El inicio de la modernidad como categoría histórica se produjo con los primeros contactos que, a través del océano, vincularon a los habitantes del Sur de Europa con las sociedades del Nuevo Mundo, relativamente frecuentes a partir del siglo XV. Sin embargo, solo la escuela descolonial ha declamado activamente el encubrimiento protagonizado por la epistemología occidental sobre los efectos adversos de este proceso, a saber; la "conquista, colonización e integración (subsunción)" del territorio y la población no europea en favor de la primacía de los

\footnotetext{
${ }^{1}$ Escribo estas páginas compartiendo mi espacio de experiencia vital entre la ciudad de Madrid, en la que resido, y el Archipiélago Canario, mi lugar de origen, una ambivalente ubicación de naturaleza posmoderna y, hasta cierto punto poscolonial, que espero que me ayude a articular un "locus de enunciación descolonial” (Mignolo, 2010: 108) con el que aproximarme a la identidad nacional española desde un punto de vista que también ponga en valor su dimensión emocional.
} 
emisarios del Viejo Continente, portadores de una "ventaja comparativa determinante" (Dussel, 1999: 148-149) para la administración del sistema mundial capitalista inaugurado entonces. Tal como afirmó Eduardo Grüner, "la construcción de eso llamado centro se hizo sobre los cimientos de la periferización del resto del mundo" (2012: 169).

Mucho antes de que Cristóbal Colón relatara estos eventos en su Diario de a bordo (1492-1503), otros materiales provistos de la misma perspectiva encarnaban la génesis que, más tarde, emplearían los delegados del Renacimiento mientras tenía lugar, como sostiene David Abulafia, El descubrimiento de la bumanidad (2009). Efectivamente, el Cantar del mío Cid (1200), la Primera crónica general de España (1284) o el Romancero viejo (1400) han sido estimadas como muestras primigenias de la exaltación de "las características épicas y heroicas [...] del poder homogéneo" (Subirats, 1994: 64) de la cristiandad en las que se sostuvieron las "convenciones legales de exclusión" del discurso de "limpieza de sangre" (Friedman, 1987: 16). Hablo de un dispositivo para la ordenación de las diferencias que operó durante la última fase de la conquista de Al-Ándalus (711-1492), un periodo marcado por la institucionalización de la represión y la eliminación física de la enorme variabilidad de estilos identitarios que entonces habitaban la Península Ibérica. Así pues, fue mediante la violencia política y militar que significó la expulsión de poblaciones como la judía y la musulmana, además de la persecución del pueblo gitano y el credo protestante, que empresas netamente católicas como la Santa Inquisición (1478-1821) se autoimpusieron como tarea "la vigilancia hacia todo foco de contagio" para la "etnogénesis española” (Stallaert, 1998: 42, 19).

Esta "manipulación totalitaria de lo universal" (Stanislas, 2004: 60), formulada principalmente sobre el relato de la fe, pero no exenta del recurso a otros marcadores coloniales y modernos como la raza, el género, la clase o la epistemología, no se detuvo en la frontera Suroeste del Viejo Occidente. Con la deriva transmarina iniciada por la recién unificada monarquía hispánica, el discurso de la pureza de sangre alcanzó una nueva dimensión al ponerse al servicio de un patrón de dominación inédito: la "colonialidad del poder" (Quijano, 2014: 312)2, una maquinaria consagrada a la producción y reproducción de la "diferencia colonial" (Mignolo, 2003: 39), la cual constituía, en palabras de Santiago Castro-Gómez:

el primer imaginario geocultural del sistema-mundo que se incorporó en el habitus de la población inmigrante europea, legitimando la división étnica del trabajo y la transferencia de personas, capital y materias primas a nivel planetario. [...] Uniendo las tesis de Quijano con las de Mignolo puedo decir que el imaginario de la blancura producido por el discurso de la pureza de sangre fue una aspiración internalizada por todos los sectores sociales de la sociedad colonial y fungió como el eje alrededor del cual se construyó (conflictivamente) la subjetividad de los actores sociales. Ser "blancos" no tenía que ver tanto con el color de la piel como con la escenificación personal de un imaginario cultural tejido por creencias religiosas, tipos de vestimenta, certificados de nobleza, modos de

\footnotetext{
2 María Lugones amplía el alcance del término acuñado por Aníbal Quijano, constatando la incidencia constitutiva de "ámbitos básicos de la existencia humana" como el "trabajo", la "autoridad colectiva", la "subjetividad/ intersubjetividad" y, sobre todo, el "sexo [...], sus recursos y productos" (en Lugones, 2008: 78). Este ejercicio, destinado a "entender los rasgos históricamente específicos de la organización del género en el sistema moderno/ colonial", tiene como objetivo denunciar el "dimorfismo biológico y la organización patriarcal y heterosexual de las relaciones sociales" que conforman su "lado oscuro" para lograr, no sólo su "reconocimiento", sino también su reformulación en una "dirección liberatoria” (Lugones, 2008: 78, 85, 98).
} 
comportamiento y (esto es muy importante) formas de producir y transmitir conocimientos (2005: 55; 60).

La legitimidad conferida a esta cosmovisión provocó una gradual "desmemorialización" (Perceval, 1997: 44-46) de la otredad con la que el Viejo Mundo interactuó a través del Atlántico. Un ejercicio materializado en la articulación de relatos tan representativos de su tradición occidentalista como Le Canarien (1402-1404) de Jean Le Verrier y Pier Boutier, la Crónica del descubrimiento y la conquista de Guinea (1448) de Gomes Eanes da Zurara o la Historia verdadera de la conquista de Nueva España (1568) de Bernal Díaz del Castillo3. Tres obras que representaron, pese a la resistencia nativa, el interés "dramático" por la "repoblación" (Pupo-Walker, 1982: 42, 18) que manifestó Europa en el Nuevo Occidente, sobrepasando con creces la mera narración épico-militar para abarcar también una evidente dimensión "semiótica" (Escobar, 1996: 382).

Sin estos dispositivos para "construir diferencias" (Estévez, 2001: 334) hubiera resultado imposible articular la hegemonía mundial que la monarquía hispana detentó entre los siglos XV y XVII. Y, mucho menos aún, podrían haberse determinado las distancias que elevaron a la moderna identidad española con respecto a su alteridad colonial, por más que, al asumir tan denodado esfuerzo de clasificación y blanqueamiento, resultara posible apalabrar la existencia de, como mínimo, dos paradojas. La primera está relacionada con un razonamiento de lo más elemental: todo ejercicio de identificación positiva tiene un lado negativo o siniestro, lo que quiere decir que toda identidad supone, además de la especificación de diversas manifestaciones colectivas del goce (jouissance), la definición de un Otro que lo amenaza, en este caso asociado con quienes quedaron al margen de la cristiandad. Mientras que, la segunda evidencia el hecho de que, a consecuencia de semejante tensión antagonista, todo acto de identificación posee una naturaleza contingente, lo que viene a demostrar que es imposible apelar a un "Nosotros" sin notar la ausencia de un Otro que, en última instancia, adquiere las propiedades de una falta constitutiva, puesto que actúa como la fuerza que propicia el eterno retorno de lo que ha sido negado o reprimido en el momento preciso en que es formulada la identidad ${ }^{4}$.

A consecuencia de este mismo "recurso", consistente en "retirar el afecto" (Nobus, 2000: 23) a los habitantes de la orilla colonial del planeta, me atrevería a afirmar que tomó forma uno

\footnotetext{
3 Se denomina "occidentalismo" a la tendencia etnocéntrica a concebir el avance colonial europeo hacia América y una parte de África durante el Renacimiento como si ambos continentes formaran una porción fundamental de Occidente. De hecho, en sus orillas fueron recreadas por igual las ficciones clásicas y medievales de inspiración cristiana que hicieron posible su concepción como una prolongación de la tierra de Jafet, ascendiente bíblico común que, desde entonces, emparentó a la población de Europa con la de estos territorios (véase más en E. O’Gorman, 1958). Además de los ejemplos ya mencionados de este estilo retórico, también son textos occidentalistas la Crónica General de España (1553), de Florián de Ocampo; la Historia General de España (1592-1605), de Juan de Mariana; el Libro de las cinco excelencias del español (1629), de Benito de Peñalosa; o la Declaración mística de las armas de España (1636), de Juan Caramuel.

${ }^{4}$ La jouissance o goce supone una modalidad positiva de escenificación de lo real, entendida como un concepto similar a la enunciación freudiana del afecto: "donde hay afecto hay jouissance" (en Fink, 1997: 212). Por otra parte, la falta en ser es enunciada como un lugar central en la concepción lacaniana del sujeto, cuya subjetividad constituye el espacio en que se simbolizan las políticas de identificación. Es más, la idea del sujeto como falta no puede separarse del reconocimiento de sus esfuerzos para "compensar su falta constitutiva en el nivel de la representación". Luego, es esta carencia, transformada en fuerza para Laclau, la que "exige que la constitución de toda identidad se lleve a cabo mediante procesos de identificación con objetos socialmente disponibles, como las ideologías políticas, los patrones de consumo y los roles sociales" (Stavrakakis, 2010: 47).
} 
de los acontecimientos historiográficos más polémicos de este periodo: la Gran Controversia. Este debate giró en torno a la posibilidad de restituir los apegos sustraídos a los diferentes pueblos indígenas que administraba el imperio hispano, extendiéndose desde finales del siglo XV hasta bien entrado el XVI para abarcar lugares tan distintos como Caparra, Valladolid, Coímbra o Chiapas. La discusión pasó a la posteridad a consecuencia de las declamaciones realizadas por sus principales protagonistas, hoy en día estimados como los primigenios precursores del Derecho de gentes, estos son, Gonzalo Fernández de Oviedo, Fray Francisco de Vitoria, Ginés de Sepúlveda o Fray Bartolomé de Las Casas, autores de textos de tanta importancia para dicha disputa como el Sumario de la natural y general historia de las Indias (1526), la Relectio de indis (1539), el Tratado sobre las justas causas de la guerra contra los indios (1550) o la Brevísima relación de la destrucción de las Indias (1552), respectivamente.

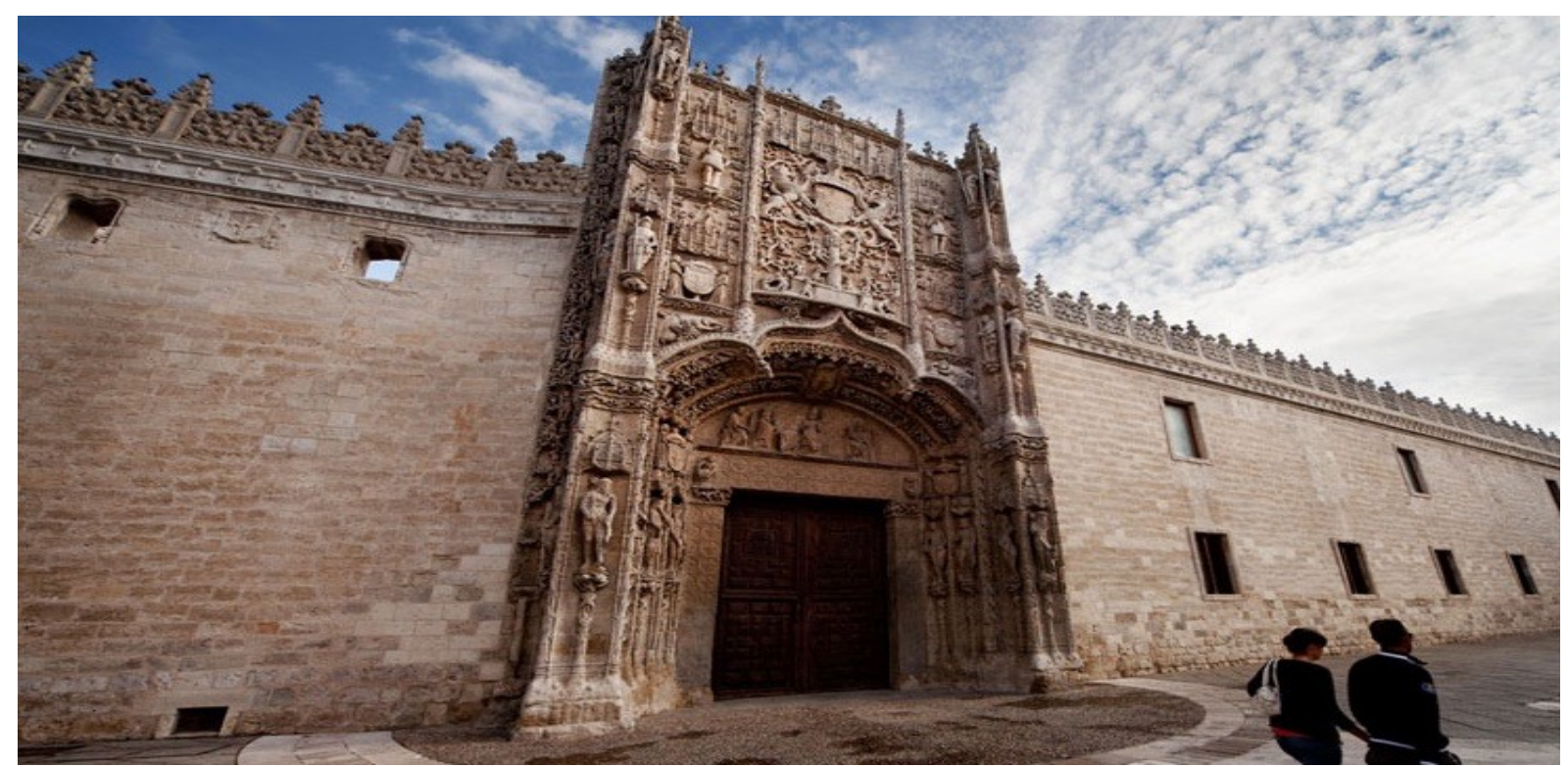

Ilustración $\mathrm{n}^{\circ}$ 1. Una de las localizaciones metropolitanas más representativas de esta polémica transmarina fue el Colegio de San Gregorio, en Valladolid, un inmueble levantado a finales del siglo XV que representa, a través de sus numerosas influencias arquitectónicas, la pluralidad reinante en la España civilizadora que trató de negar sus herencias musulmana y hebrea, además de jerarquizar el linaje de las poblaciones de África y América. Aunque esta manera de obrar parece contradecirse con la arquitectura que caracteriza a este edificio, que mezcla elementos propios de las estéticas gótica, renacentista y mudéjar. De todo el inmueble, lo más destacable es su fachada, construida en forma de retablo con representaciones de lo más llamativas de las poblaciones no europeas que fueron reprobadas en el interior de sus estancias en numerosas ocasiones. Como diría Žižek, "la represión y el retorno de lo reprimido son lo mismo y forman un único proceso" (2010: 29).

El resultado de la Gran Controversia es sobradamente conocido. De manera pautada se impusieron los planteamientos propuestos por el padre Las Casas, fundamentados en la defensa de la gentilidad de las poblaciones amerindias en detrimento de las musulmanas, hebreas y de origen subsahariano, las cuales, en no pocos casos, continuaron segregadas, o, lo que es peor, condenadas a soportar la esclavitud. No obstante, tal desenlace no libró a la naciente identidad pre-nacional española de sufrir las consecuencias de su propia perversidad: la desmentida de los 
efectos más sangrantes de la aplicación del ideario de la pureza de sangre como su principal fuente de legitimidad; esto es, el reconocimiento y la negación simultánea de la "violencia epistémica" (Spivak, 2003: 317) aparejada no sólo a la expansión de su modelo colonial, sino también al establecimiento de su propio autorretrato 5 .

En resumen, la progresiva imputación/asunción de la culpabilidad ibérica en las pérdidas ocasionadas por un estadio tan problemático, acabó por convertirse en uno de los ejes que dinamitaron su auto-inducida centralidad. Podría decirse incluso que, su predominio global se consolidó a través de la tendencia fetichista a abstraerse de un "trauma colonial" (Mezilas, 2015:7) que acabaría teniendo, a posteriori, mucho que ver con su decadencia, causada, sin lugar a dudas, por el avance de las luchas anticolonialistas, pero también por el empuje del nuevo imperialismo que encabezaron, fundamentalmente, Inglaterra, Francia y Holanda. De hecho, ya en el ocaso del siglo XVII, estas tres entidades se convirtieron en los mayores voceros de la leyenda negra de España, un sólido contra-discurso destinado a horadar su supremacía cumpliendo su cometido solo con reproducir en negativo algunos de los planteamientos exhibidos durante la Gran Controversia. Así pues, se podría sostener — no sin cierta ironía- que la primera fase de construcción moderna de la identidad española terminó de la misma forma en que había empezado doscientos años atrás: con la desmentida de su investimento como imperativo universal.

\section{SEGUNDA OLEADA: NACIONALISMO E IMAGINARIO CIENTÍFICO DE LA RAZA}

El comienzo de la segunda oleada de exaltación de la identidad española coincide en el tiempo con lo que Michel Foucault ha denominado como el nacimiento de la biopolítica, un proceso concebido como resultado de la "mutación epistemológica" (2007: 259) que experimentaron la mayoría de las sociedades modernas del siglo XVIII, alumbrando el surgimiento de un nuevo "régimen gubernamental": el "liberalismo" (2007: 41). Desde entonces, este modelo ha sido el principal instigador de las distintas tecnologías destinadas a garantizar el surgimiento del Estadonación como unidad política indispensable para la consolidación de las aspiraciones globales del sistema capitalista.

De nuevo en España, es preciso detallar que la primigenia implementación de estos diseños no fue fruto de la inventiva de sus dirigentes, sino que respondió a la nueva "ilusión egocéntrica" (Toynbee, 1987:70) que representó la naciente primacía noreuropea durante la

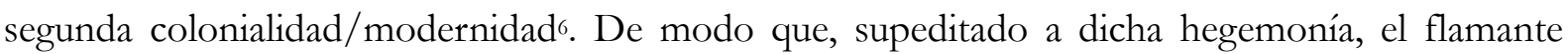
Estado Borbón hizo suyas las preocupaciones de sus pares continentales, materializadas en la

\footnotetext{
${ }^{5}$ La desmentida "es el mecanismo típico de la perversión”. De acuerdo con Freud, "en la perversión está en juego el modo en que se registra la castración". El "sujeto perverso" —el fetichista_ "se niega a reconocer esta percepción traumática". De manera que, "la diferencia radica en el hecho de que el fetichista sabe acerca de la castración, pero trata de olvidarla mediante la formulación de una "estrategia defensiva" consistente en la elaboración de una "formación sustituta" de la falta: "el fetiche" (Dor, 1988: 97).

${ }^{6} \mathrm{Me}$ refiero a este periodo como segunda colonialidad/modernidad con el ánimo de participar en uno de los debates fundacionales de los estudios descoloniales, en el que me posiciono con quienes han tratado de dividir el desarrollo del capitalismo moderno en dos fases: la que dio comienzo con el Renacimiento hacia el año 1400 y la que empezó a definirse con la Ilustración a partir del 1700 (véase más en Dussel, 1992 y Mignolo, 2003).
} 
aplicación del proyecto absolutista una vez terminada la Guerra de Sucesión (1791-1714). Ello supuso un aumento de la centralidad gubernamental sobre su economía y, en especial, su fiscalidad y mercados, favoreciendo entre sus élites la toma de conciencia sobre la importancia de su población como recurso económico para el Imperio. Tal como lo sostuvieron pensadores hispanos de la época, como Gaspar Melchor de Jovellanos, Pablo de Olavide o Pedro Rodríguez, el liberalismo dotó de una inteligibilidad inédita a los nacionalistas españoles, a los que, además de serle confiada la tarea centenaria de garantizar entre sus coterráneos la pureza de fe, también les encomendó la labor de "regular los grandes procesos biológicos" que afectaron a su población, como la "natalidad, mortalidad, morbilidad, vivienda, vejez, etc.", con el fin de 'optimizar' sus condiciones de vida conforme a "una lógica productiva” que actuó, al servicio del Estado-nación, "sobre los cuerpos individuales a partir de un estándar de normalidad" (Vázquez, 2009: 10).

Este "cambio de mentalidad" (Toulmin, 1990: 30) contribuyó al enaltecimiento del positivismo como método de conocimiento por excelencia tanto en el Viejo como en el Nuevo Occidente, tras conferir a la ciencia la legitimidad gnoseológica para detentar el "punto cero de observación" (Castro-Gómez, 2010: 27), interpretación e intervención en la realidad. Al tiempo que, semejante mutación epistémica facultó a los primeros empiristas para el ensamblaje de uno de los constructos teóricos de mayor transcendencia de toda la modernidad: el imaginario científico de la raza, un dispositivo enteramente destinado a evaluar y normalizar la 'calidad' biopolítica de las poblaciones computadas por la dialéctica liberal. Y, todo ello, sin dejar de reproducir las principales taxonomías que la colonialidad había inaugurado previamente:

La idea de raza organiza la población mundial en un orden jerárquico de personas superiores e inferiores que se convierte en un principio organizador de la división internacional del trabajo y del sistema patriarcal global. Contrario a la perspectiva eurocéntrica, la raza, el género, la sexualidad, la espiritualidad y la epistemología no son elementos añadidos a las estructuras económicas y políticas del sistema mundial capitalista, sino una parte constitutiva integral e imbricada del amplio y entramado 'paquete' llamado el sistema mundo (Grosfoguel, 2006:19).

De la mano de la ciencia, la raza se consolidó como uno de los marcadores preferentes de las desigualdades humanas, anidando en conceptos fundamentales para la vertebración del "proyecto ilustrado" (Reale y Antiseri, 1998: 837-838), como el sujeto, la historia o la nación. De manera que, el racismo científico quedó convertido en la mejor maquinaria para apuntalar el poderío de las principales naciones europeas, las cuales, aún sin renunciar a la "diferencia colonial", también empezaron a concebirse en arreglo al ideario de la "diferencia imperial" (Mignolo, 2003: 43), una categoría habilitada para clarificar el papel secundario que cumplieron, desde entonces, Anciens Régimes como el Reino España. En este sentido, se podría aseverar que el propósito de esta nueva desmentida no fue otro que la consolidación de la preeminencia de los nacientes imperios del Norte de Europa, que bajo ningún concepto se plantearon renunciar a la colonialidad como "patrón mundial de poder capitalista" (Quijano, 2014: 285), por más que para lograr tal fin fuera preciso especificar la raza que caracterizaba a todos y cada uno de los pueblos del planeta.

En arreglo a esto, el nacionalismo español del siglo XVIII y sobre todo del XIX, podría describirse como una evidente manifestación de la ya mencionada voluntad de saber y del ser, 
encarnada por una oligarquía metropolitana que optó por mimetizarse con las estructuras del Estado con un objetivo declarado: imponer su aventajada "perspectiva" (Mannheim, 2004: 303), o, por decirlo mejor, su "sentido común" (Gramsci, 2007: 366) sobre la gran cantidad de territorios y cuerpos que permanecieron sujetos a su imperio. Solo así, esta minoría dirigente logró actualizar sus narrativas identitarias, primero en términos románticos y más tarde racionalistas, expandiendo sus pretensiones totalizantes bajo la apariencia de una nueva apuesta por la plenitud nacional. Ello se tradujo en una novedosa apelación a la imagen idílica del goce hispano, en esta ocasión respaldado ya no solo por el ethos cristiano, sino también por la incidencia desigual de disciplinas científicas como la economía, la biología, la arqueología, la medicina, la historia, la geología o la antropología física. Aunque es cierto que la implantación de cada una de ellas dependió de la pericia de sus valedores para abarcar el contexto "limitado" y "soberano" que, desde ese momento, supuso la "nación" (Anderson, 2007: 23) tanto para las ansias de las élites liberales como para las realistas, visto que, ambos bandos apelaron por igual a la población para que se imaginara dentro de los márgenes que contenían sus respectivas ideas de España?.

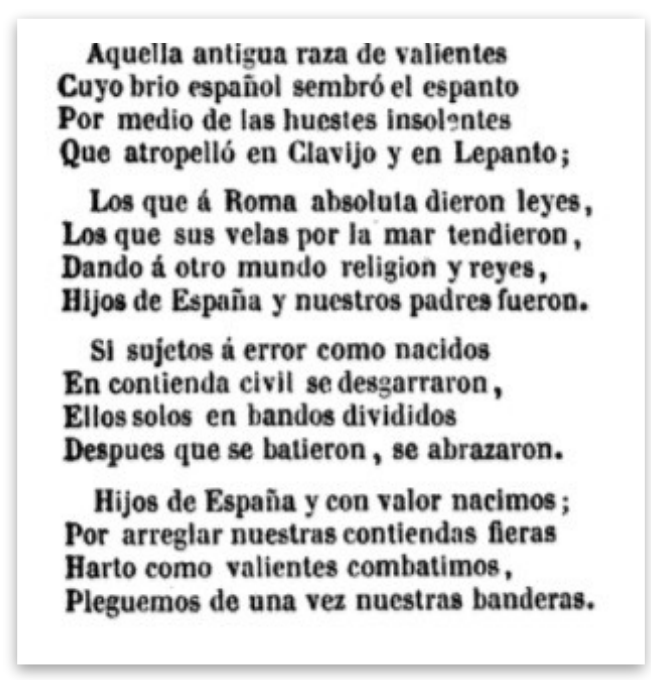

\begin{abstract}
Ilustración $\mathrm{n}^{\mathrm{O}}$ 2. Digitalización de una parte del poema de José Zorrilla Generosos como españoles (1839), presente en una antigua edición de su Obra Poética (1847) en la que se aprecia una traducción en verso del imaginario de la raza, aderezado por la reiteración de la lógica renacentista e ilustrada responsable de la fusión de "lo Occidental latino" con "lo griego Oriental". Dicha operación estaría representada, en este caso en particular, a través del enfrentamiento de la tradición hispana con la civilización andalusí en la Batalla de Clavijo (844), y con el "mundo turco" en la Batalla de Lepanto (1571), "olvidando" así los puntos de sutura que Enrique Dussel asegura que compartieron ambas sociedades, como su "origen helenístico-bizantino", por ejemplo. El resultado de este ejercicio permite construir una "ecuación falsa" sobre los orígenes de las naciones europeas, según la cual, lo "Occidental = Helenístico + Romano + Cristiano". De modo que, se podría decir que el eurocentrismo racista con el que Zorrilla se muestra perfectamente alineado, está basado en una "invención ideológica" que "rapta a la cultura griega como exclusivamente 'europea' y 'occidental”" para atestiguar que, desde la "época griega y romana,
\end{abstract}

\footnotetext{
7 A este respecto, me gustaría reseñar tres pioneros ejemplos del patriotismo de este periodo mediante el trabajo de autores identificados con tales posiciones ideológicas. Estos son los casos de los hermanos Pedro y Rafael Rodríguez Mohedano y su Historia literaria de España (1766); el Teatro histórico-crítico de la elocuencia española (1786), de Antony de Campany y, la más conocida Historia de los heterodoxos españoles (1794), de Marcelino Menéndez Pelayo (véase más en Álvarez y Fuente, 2017).
} 
dichas culturas fueron el 'centro' de la historia mundial” (1993: 43-44). Este ejercicio los vinculaba, en pleno siglo XIX, con los deseos truncados del nacionalismo español de recuperar su posición hegemónica en el sistema mundial capitalista.

El diputado doceañista Agustín Argüelles resumió con claridad todo este proceso durante la promulgación de uno de los hitos fundacionales del nacionalismo español: la Constitución de 1812. Al calor del mismo, este formuló una de sus sentencias más recordadas: "españoles, ya tenéis patria" (en Álvarez, 2001:129). Toda una declaración de intenciones sobre el destino que debía alentar, en plena Guerra de Independencia (1808-1814), el "espíritu nacional” (Campany, 1808: 75) encerrado en la que fuera la primigenia carta magna de la historia del país. De hecho, la performance constituyente de Cádiz supuso uno de los primeros intentos de asentar un retrato identitario en completa sintonía con el ideario liberal. Tanto, que al asumir en el texto que la nación hispana era el resultado de "la reunión de todos los españoles de ambos hemisferios"; esto es, la suma de la población enclavada en la orilla moderna y colonial de su imperio, otorgó a esta en exclusiva, en detrimento del poder absoluto de la monarquía, el "esencial" ejercicio de su "soberanía" (1812: 3).

El final de esta maniobra, que continuó excluyendo del diseño imperial a la otredad racializada que conformaban "las 'castas' de indios o negros" (Álvarez, 2001: 193), no llegó, sin embargo, hasta la consumación de dos acontecimientos fundamentales para comprender el cierre de esta segunda oleada: la restauración del absolutismo en España (1814-1833) y la emancipación de las jóvenes naciones americanas (1810-1833). Dos eventos que, en lugar de alejar a sus élites dirigentes de la influencia del "fanatismo castizo" (Álvarez, 2009:53), lo que consiguió fue justo lo contrario. De modo que, aún bajo el paraguas de la colonialidad, el Reino de España trató de competir con el avance de los imperios europeos emergentes mediante la expansiva evocación de una singular genealogía nacionalista que, entre otras acciones, llevaría a personalidades políticas de la talla de Emilio Castelar, a atribuir a posesiones coloniales como la isla de Puerto Rico y Cuba el "interés superior" de la "conservación de la raza latina” (en Rama, 1982: 245)8.

Sólo así puede entenderse el eco que alcanzaron en el mundo hispano las jerarquías raciales inspiradas en el pensamiento de Carlos Linneo, Johann Friedrich Blumenbach, Arthur de Gobineau o el mismísimo Immanuel Kant, las cuales, en el caso particular de España, no reemplazaron al "protorracismo religioso" (Aranzadi, 2001: 906) de la pureza de sangre, que aún legitimaba la labor expiatoria — también frente a la diversidad ideológica- de instituciones claramente inquisitoriales como las Juntas de Fe (1823-1834). Ello quiere decir que, más que una sustitución, lo que se produjo durante esta fase fue una fusión entre el racismo científico y el ethos cristiano como parte de "una estrategia de racialización" (Torres, 2011: 48) que acabaría por

\footnotetext{
8 La "raza latina" fue enunciada como mecanismo de defensa desde el que reposicionar América y España "estratégicamente" respecto a los principales "impulsores de dicha ideología racial biológica: el imperialismo inglés y el francés, así como el emergente imperialismo norteamericano". Este "nuevo discurso", que "se desarrolla desde la Ilustración [...], se consolida en la década de 1850", justo en el momento en que "el concepto de 'raza latina' comienza a formularse a ambos lados del Atlántico", articulándose de manera "triangulada" en el siglo XIX para convertirse en el xx en "la ideología dominante de los países hispánicos" (Gabilondo, 2009: 795).
} 
equiparar el avance del imaginario castizo con el desarrollo de un proceso de castración simbólicat. Aunque es cierto que este enésimo intento totalizador volvió a encarnar el signo de una paradoja, pues, tras la centrífuga definición racial del "tipo español" (Olóriz, 1894: 277) vendría la centrípeta respuesta de los nacionalismos vasco, catalán y gallego en su empeño por alcanzar un mismo objetivo: "asignar a cada raza el lugar que le corresponde en la civilización" (Murguía, 1865, I: 2) ${ }^{10}$. Como se puede comprobar, no se equivocaba George W. Stocking cuando sentenciaba que, en último término, "raza" y "nación" son conceptos aplicables a "diferentes niveles de una misma pirámide" (1985: 7-8).

\section{TERCERA OLEADA: MUERTE Y RESURRECCIÓN NACIONAL}

Siempre hay "algo de verdad", afirma Slavoj Žižek, "en el juego de palabras entre 'historia' e "histeria"' (2010:43) y, a juzgar por la manera en que España acabó el siglo XIX y empezó el XX, este aserto resulta de lo más verosímil. Para demostrarlo, bastaría con aproximarse a la cuantiosa historiografía que detalla la situación en que se encontraba el país durante dicho periodo, marcado por una dura competencia entre distintos sectores ideológicos que pretendían hacerse con las riendas del Estado. Me refiero, por ejemplo, a los progresistas, entre los que podía contarse a liberales moderados y exaltados, algunos de ellos identificados con el federalismo que imperó en la última fase del Sexenio Democrático (1868-1874), pero también a los monárquicos, donde conservadores más o menos liberales y tradicionalistas católicos, como los carlistas, aún aludían a la corona como fuente de legitimidad para imponer su totalizadora fantasía nacional. No obstante, solo una porción de este enorme abanico ideológico llegó a influir efectivamente en el destino del país tras la Restauración Borbónica (1874-1931).

La Primera Guerra del Rif (1893-1894), secuela de la Guerra de África (1859-1860), dejó bien claras las intenciones de los dirigentes realistas para combatir el "germen particularista" (Ortega, 1921: 72), una génesis a la que también aludieron quienes hablaron, siguiendo a Max Nordau (1892), de la degeneración de la raza y la nación española, especialmente tras la derrota cosechada en la guerra hispano-estadounidense y el final de su mandato colonial en las Islas Filipinas, Cuba y Puerto Rico (1898), a las que se unieron un año más tarde las Marianas,

\footnotetext{
9 En los "rituales de investidura", incluidos los de tipo racista, los elementos que "simbolizan el poder" ponen al sujeto que los adquiere "en posición de ejercer el poder" (Žižek, 2010: 42). Para ello se recurre, como diría Max S. Hering Torres, a "símbolos corporales y culturales" (2011: 47-48) que son portados para ejercer el poder y, como tales, nos castran. En sentido estricto, la castración, "lejos de ser lo opuesto al poder, es un sinónimo del poder" (Žižek, 2010: 43), lo cual, aplicado al contexto hispano, permitiría afirmar acaso que, "sólo a partir de la experiencia colonial tardía, el español se haya empezado a imaginar como blanco" (Torres, 2011: 44), como símil racial de un "tipo hegemónico de subjetividad” y "conocimiento" (Castro-Gómez, 2005: 61).

10 Para Federico Olóriz Aguilera, en España se había producido, fundamentalmente, la mezcla de "dos razas": la "íbera" y la "céltica", que "desde los tiempos más remotos" se habían mantenido "con bastante uniformidad en casi toda la extensión del territorio nacional", lo que conferiría al "pueblo español” la consideración de ser "uno de los más puros de Europa" (1894: 274-278). Según Pompeu Gener i Babot, en el caso del "pueblo catalán" se produjo el "triunfó del ario", que "se sobrepuso" a la "inferiodidad" de la "sangre semítica" española (1887: 253, 264). Algo similar a lo planteado por Manuel Murguía cuando afirmaba que "Galicia podrá siempre enorgullecerse" por contarse "entre las comarcas habitadas por los decendientes de los pueblos de Aria" (1865, I: 200). Telersforo de Aranzadi y Unamuno, por su parte, también estableció una "caracterización de los vascongados como raza" en base a sus "relaciones con las razas primitivas de Europa" (1889: 5).
} 
las Carolinas y Palaos. Ahora bien, junto a estas persistentes "retóricas de muerte", que tanto exacerbaron la histeria de sus élites intelectuales, es cierto que resultaron cada vez más recurrentes las apelaciones a su "resurrección" (Juliá, 1998: 155), una tarea en la que se implicaron pensadores tan conocidos como Ángel Ganivet, Joaquín Costa, Pio Baroja, José Martínez Ruiz 'Azorín', Ramiro de Maeztu o Miguel de Unamuno. Todos ellos presentes en publicaciones imprescindibles para comprender la pluralidad que caracterizó a este resurgir nacionalista, como la Revista contemporánea (1875-1907), La España moderna (1889-1914), Germinal (1897-1899) o Alma Española (1903-1904) ${ }^{11}$.

Fue el conservadurismo, sin embargo, el que se impuso en este ejercicio de reificación patriótica, lo que explica el hecho de que su viejo "orgullo imperial” (Krauel, 2013: 176) volviera a emerger acompañado de una irrefrenable necesidad de blanquear su pasado. Y, cuando digo blanquear, me refiero al proceso que estudiosos como Christopher Schmidt-Nowara han relatado como el establecimiento de una "contraparte" a su leyenda negra: la "Leyenda Blanca sobre la benevolencia española" (2005: 1), una maniobra narrativa destinada a restablecer los "puntos nodales" (Laclau y Mouffe, 2004: 152-153) que habían presentado al colonialismo hispano como la secuela de un loable ejercicio de civilización. Así, este entramado significante, además de volver a América de la mano de un refinado hispanismo, hizo lo propio en el Golfo de Guinea a través de la enésima desmentida que supuso el hispanotropicalismo y la orientalizante acción africanista implementada en Marruecos y el Sáhara Español ${ }^{12}$.

Esta nueva exaltación castiza de la raza y la nación dio pie a un inusitado tráfico de afectos en la escena hispana durante el primer tercio del siglo XX. De hecho, casi todo el espectro ideológico del país, aún con sus diferencias, participó de esta suerte de resurrección nacional a

11 A menor escala que la etnogénesis vasca, la Renaixença catalana y el Rexurdimento gallego (Prat et al., 1991), cobró protagonismo el ejercicio de positivación que Blas Infante implementó sobre el "estigma africano" (en Stallaert, 1998:91) que durante siglos lastró las representaciones culturales e históricas andaluzas, y también la resignificación del colonialismo español en Canarias con que Secundino Delgado barnizó su práxis política (Sánchez, 2007). Y así sucedió mientras el regeneracionismo hispano se proyectaba como fantasía hegemónica entre los intelectuales de generaciones como la novecentista, la del 14 o el 27, que continuaron alimentado, desde sus distintivos puntos de vista, el citado debate sobre la 'cuestión nacional'. Despuntaron, a este respecto, obras tan señeras como El problema español (1911), de Manuel Azaña; la España invertebrada (1921), de Ortega y Gasset; Guerra en España (1954), de Juan Ramón Jiménez; o España, sueño y verdad (1965), de María Zambrano.

$12 \mathrm{El}$ hispanismo es reelaborado con el final del colonialismo hispano en América, cuando "el discurso de la raza latina adquiere toda la flexibilidad que supone su doble origen genealógico y biológico", convirtiéndose, especialmente en la Península Ibérica, "en un discurso reaccionario y melancólico de pérdida colonial” (Gabilondo, 2009:812). Destacan, como ejemplo de tales planteamientos, las premonitorias Cartas americanas (1889), de Juan Valera, El sino de la hispanidad (1930), de Francisco Mayán o la Defensa de la hispanidad (1934), de Ramiro de Maeztu. El orientalismo, por su parte, debe entenderse como "un modo de discurso" que define, al interior de la tradición cultural europea, esa vasta e imprecisa escena geopolítica que conformaba "el Oriente" (Said, 2007: 20). Aunque en el caso español incumbe, como puntualiza Aurora Rivière Gómez, a los "estudios árabes y hebreos" (2000: 13). Víctor Morales Lezcano - más pragmático_ prefiere hablar de africanismo como el resultado de la "voluntad de estudio y reconocimiento del vecino continente con vistas a intervenir" en él (1988: 18), tal como lo hacen Isaac Muñoz en La agonía del Mogreb (1912); los Estudios sabarianos (1955), de Julio Caro Baroja; y Las tribus del Sáhara (1973), de José E. Alonso. En último lugar, el hispanotropicalismo, como apunta Gustau Nerín, subordina los preceptos ya citados a la "innata vocación africana" de España, su "tendencia misionera", "la ausencia total de actitudes racistas y la difusión del mestizaje” (1998: 12) bajo su mandato en Guinea Ecuatorial. Sobre la acción española en esta colonia, vale la pena destacar la intuitiva gramática de Ángel Ganivet en su Idearium español (1896), al que le seguiría la Guinea Española (1944), de Agustín de Saz; y España y la Guinea Ecuatorial (1968), de Fernando Castiella. 
través de la elaboración de lo que Laura Berlant ha definido como "políticas del sentimiento" (2001: 30), un ejercicio de reorganización del poder destinado a intervenir sobre un contexto marcado por sus altos niveles de antagonismo, desde el reinado de Alfonso XIII (1903-1921) a las dictaduras de Miguel Primo de Rivera (1921-1930) y Dámaso Berenguer (1930-1931), pasando por los gobiernos conservador y progresista de la II República (1931-1939). No obstante, todos y cada uno de estos regímenes fracasaron en sus distintivos intentos de aplacar el disenso imperante en su sociedad, especialmente el modelo autoritario que se alzó contra el orden democrático de la II República (1931-1939): el franquismo.

En efecto, la prolongada dictadura que acaudilló Francisco Franco (1939-1975) se obsesionó con la imposición de su particular 'cruzada' nacional, apelando a un retrato patriótico afanado, una vez más, en describir la "historia", la "lengua", el "espíritu religioso", la "raza" y la propia "nación" como una "unidad de destino en lo universal" (Falange Española, 1933: s/n). Esto es, una monolítica definición de la identidad española que basculó a conveniencia entre los excluyentes principios del fascismo y los preceptos melancólicos del nacional-catolicismo. Así pues, ni las 'innovaciones' aplicadas a la experiencia civilizadora que experimentó el país a partir de 1900, que insistían en la existencia de lazos 'innegables’ entre España y África, demostrables mediante categorías raciológicas como la del "íbero-bereber" (Gil, 1952: 88), impidieron que muchas de las prácticas asociadas a su colonialidad histórica volvieran a ser aplicadas, especialmente a cuantos fueron señalados como "enemigos de la Patria" (Franco, 1936)13.

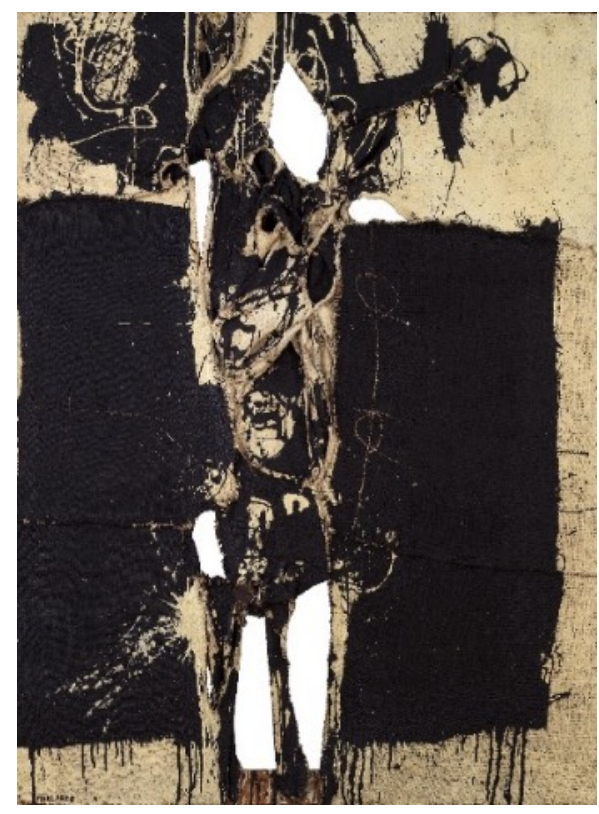

\footnotetext{
${ }^{13}$ Gustau Nerín asegura en La guerra que vino de Affrica (2005), que desde el inicio de la Guerra Civil los golpistas llevaron a cabo un sofisticado ejercicio de "desplazamiento de la barbarie" desde los continentes americano y africano a la Península Ibérica — sin que ello implicara el cese de la colonialidad en tales territorios. Por eso existen tantas referencias rubricadas por dirigentes franquistas en las que el bando republicano, que llegó a ser descrito como los "moros del Norte", es afectado por las mismas maquinarias que estos habían aplicado a los pueblos "salvajes" con los que España se había 'encontrado' en el Atlántico. Esta estrategia de subalternización resultó especialmente útil a la hora de "legitimar" la equiparación del adversario político con quienes aún eran categorizados como "seres colonizables" (2005: 193-223). Y ahí están las Pastorales de la Guerra de España (1955), de Isidro Gomá; España, un enigma histórico (1957), de Claudio Sánchez Albornoz; o la Evolución de las ideas sobre la decadencia de España (1962), de Pedro Sáinz Rodríguez para demostrarlo.
} 
Ilustración $n^{\circ}$ 3. Manolo Millares fue un pintor informalista cuya actividad creativa discurrió en plena dictadura. Quizás por eso, no resulta extraña la presencia en su obra de homúnculos (1959) como el que da nombre al cuadro que aquí reproduzco, en el cual, una figura antropomórfica luce mortalmente herida en colores blancos, rojos y negros. Por medio de esta representación de la violencia y la muerte, Millares busca exorcizar a los fantasmas que "no han cesado de asediar su espíritu" (França, 2003: 131), estableciendo una dura crítica al orden y la razón que había legitimado semejantes cicatrices. Dicho de otro modo, sus arpilleras simbolizan una especie de evocación crítica de la civilización Occidental, llamada a reunir, bajo una misma declamación humanista, a los millones de víctimas que esta se ha cobrado desde el inicio del colonialismo hasta el ascenso del fascismo cinco siglos después.

Tal como lo planteó Aimé Cèsaire en su particular definición sobre la "crisis de Europa", que, no en vano, pondría fin a la modernidad, el fascismo fue el sistema político que reveló, por primera vez, a la población del Viejo Continente la "perversidad" consustancial de las violencias coloniales (en Maldonado-Torres, 2006: 185). Es más, fruto de las profundas heridas que estas dejaron en sus principales metrópolis durante la II Guerra Mundial (1939-1945), se alcanzaron los consensos que propiciaron, no sólo la creación de la Organización de las Naciones Unidas (1945) —en cuyo seno se materializó, pese a su rivalidad con el mundo soviético, la primacía estadounidense sobre España y Europa gracias al éxito de iniciativas como el Plan Marshall (1948-1952) - sino también el inicio de la descolonización en Asia y África, además de la promulgación de las sucesivas Declaraciones sobre la raza emitidas por la UNESCO a partir de 1950. En resumen, el nuevo contexto internacional horadó las bases nacionalistas, racistas y colonialistas en que se había definido la pose histérica de las élites franquistas, las cuales, si lograron apuntarse algún logro, fue prorrogar la asimilación hispana de algunos de los preceptos que marcaron el inicio de la nueva era posmoderna y poscolonial. Amplificando el juicio que Herbert Ramsden dedicó en su día a Ángel Ganivet, el mayor éxito de quienes acapararon las estructuras de saber y del ser en España durante esta tercera oleada de exaltación nacionalista, consistió en su singular manera de enunciar "la victoria desde la derrota" (1967: 188).

\section{CUARTA OLEADA: TRANSICIÓN A LA COLONIALIDAD GLOBAL}

La Transición democrática (1975-1986) marcó en España el inicio de su última fase de exacerbación identitaria, una etapa habitualmente retratada como expresión del deseo mayoritario de su población de dejar atrás los excesos de la dictadura. No obstante, entre las diferentes 'opciones de cambio' disponibles durante este periodo, todavía imbuidas en la lógica dicotómica de la Guerra Fría (1945-1989), solo una logró consolidarse: la segunda restauración de la monarquía bajo las reglas de juego de la "posdemocracia consensual” (Rancière, 2012: 152). Este nuevo modelo desmanteló buena parte de sus estructuras coloniales en el continente africano, seriamente mermadas tras la disolución del Protectorado de Marruecos (1958), la independencia de Guinea Ecuatorial (1968) y la fallida descolonización del Sáhara Occidental (1975), mientras proponía para el resto del país una solución basada en la distensión de sus estructuras “castellanizantes" (Fox, 1997: 209) bajo la promesa de asumir una mayor descentralización. Y para cumplir dicho compromiso, el gobierno liberal de Adolfo Suárez (1976-1981) lideró la 
implementación del Estado de las Autonomías (1978-1983) como 'paso intermedio' entre el “Estado-nación” y el "Estado plurinacional” (Gispert y Prats, 1978: 43).

Todos estos acontecimientos, junto a otros de similar importancia, como el ingreso de España en la Organización del Tratado del Atlántico Norte - la OTAN- (1982) o en la Comunidad Económica Europea (1986), que no invirtieron su condición subalterna frente a sus vecinos Noreuropeos y la "soberanía imperial" estadounidense (Negri y Hardt, 2009: 175), fueron los que obraron, sin embargo, el 'milagro español'. Un proceso consistente en la apresurada edulcoración de su arcaica modernidad, todavía atrapada por el patriotismo racista, el fundamentalismo católico y el orgullo imperial, para abrazar su actual condición posmoderna y, en cierta medida, también posnacional y poscolonial14. Así fue como las élites españolas de finales del siglo XX calmaron sus ansias de equipararse con el contexto que volvería a convertirse en su principal marco de referencia: el hemisferio occidental. Aunque es cierto que este renovado 'sueño' occidentalista no tomó cuerpo hasta que tuvo lugar un momento clave en su agenda performativa: el año de 1992, fecha en que se cumple el quinto centenario de la llegada de Colón a América.

No por mera casualidad, esta efeméride coincidió en el tiempo con acontecimientos de gran utilidad para ilustrar la deriva amnésica que protagonizaron los sucesivos gobiernos socialdemócratas de Felipe González (1983-1996), incapaces de desapegarse de muchos de los "principios ideológicos" promovidos años atrás por el "Franquismo" (Cruz, 2005: 199). Hablo, por ejemplo, del nacionalismo-kitsch que su ejecutivo proyectó a través de la Exposición Universal de Sevilla (la Expo'92), los Juegos Olímpicos de Barcelona o el nombramiento de Madrid como Capital Cultural Europea. A los que habría que sumar la entrada en vigor de los Acuerdos de cooperación en materia religiosa, que por primera vez en cinco siglos, oficializaron las relaciones entre España y las depuestas confesiones hebrea, protestante y musulmana; si bien es verdad que estos remitieron a un laicismo que, finalmente, resultó ser "más simbólico que real" (Astor y Griera, 2016: 265)15.

En síntesis, el país ibérico trató de recomponerse en la escena internacional, llegando incluso a participar, aunque nuevamente de forma subsidiaria, en la suscripción del Tratado de Maastricht (1992), que no en balde, desembocó en la articulación de una renovada plataforma

\footnotetext{
14 Esta última afirmación podría resultar problemática, sobre todo si se atiende a la naturaleza dislocada de los nuevos patriotismos, permeables al carácter "multiétnico" y "transfronterizo" (Appadurai, 1996: 176) que presentan la mayoría de los Estados nacionales contemporáneos. Asimismo, tampoco sería posible hablar de un posnacionalismo asentado en una España en la que las tensiones territoriales todavía se leen como una indeclinable 'cuestión de Estado'. Mientras que, el carácter ambivalente de algunas de sus regiones, ubicadas fuera de los márgenes del continente europeo — como las ciudades de Ceuta y Melilla, además de las Islas Canarias_ certifican la pervivencia de una especie de "nostalgia imperialista" (Rosaldo, 2000: 94), así como la continuidad en el tiempo de algunas de sus más arcaicas formas de colonialidad.

15 María Rosa de Madariaga asegura que, «después de la instauración de la democracia» se desarrolló en España "un interés renovado por Al-Andalus" y el exotismo orientalista "como modelo de sociedad plural y diversa" que oponer "a la doctrina oficial impuesta por el franquismo" (2000: 82). De esos años, además de la reedición de buena parte de las obras de Jaume Vicens Vives y Américo Castro, en especial de la Historia social de España y América (1982) de Vives, datada originalmente en 1957, y de España en su historia (1983) de Castro, editada por primera vez en 1948, cabe mencionar las Crónicas sarracinas de Juan Goytisolo; las Huellas del Islam en la literatura española (1989), de Luce López Baralt; y La extraña seducción (1993), de José Antonio González Alcantud.
} 
para la gobernanza del Viejo Continente: la Unión Europea (1993- ), una comunidad de carácter posnacional, concebida para aligerar el "bagaje institucional" y el "peso ideológico" que los Estados miembros habían experimentado en "el sentido negativo del nacionalismo" (Shaw, 2000: 74). Y que, junto a la expansión del «orden social libidinal» del capitalismo de consumo (Lipovetsky, 2000: 63) y la "financiarización total del planeta" (Spivak, 2010: 221, nota al pie), contribuyó inequívocamente a reforzar su investimento como ente poscolonial mediante una 'transición' cuyo potencial residió en el modo en que:

rearticul[ó] la diferencia colonial en una nueva forma de colonialidad del poder que ya no está localizada en un Estado-nación o un grupo de Estados-nación, sino como colonialidad global transnacional y transestatal. Tiene sentido, en esta argumentación, considerar el liberalismo como una nueva forma de civilización y no sólo como una nueva organización económica. La "globalización" se convierte así en una imagen del nuevo diseño civilizador. [Y, en la medida en que la colonialidad es la cara oculta de la modernidad, la "modernización del proyecto neoliberal hoy implica necesariamente nuevas formas de colonización" [cursivas añadidas] (Mignolo, 2003: 356, 23).

Solo así, la Europa comunitaria se convirtió, bajo el auspicio de los Estados Unidos, el Fondo Monetario Internacional y el Banco Mundial en uno de los principales puntos de referencia para una colonialidad que, como patrón posmoderno del saber y del ser, abarcaba ya en su conjunto el sistema mundial capitalista. Todo ello al mismo tiempo que en España, especialmente durante la presidencia conservadora de José María Aznar (1996-2004), se intensificaba el debate acerca de los límites de su autorretrato nacional, dando origen a un periodo que ha sido bautizado por Antonio Francisco Pedrós-Gascón como un Nuevo 98. Es decir, como una nueva 'muerte y resurrección' patriótica sostenida en la neurosis de defensa que volvieron a articular sus clases dirigentes como "respuesta" a la "europeización de la sociedad española" (2009:29). Luego, su sintomática apelación a la lengua castellana, el pasado imperial del país y a su unidad de destino no ha hecho sino escenificar el retorno fantasmal de su identidad como imperativo universal, tantas veces enaltecida como significante maestro de un nacionalismo que no ha logrado alejarse de esa forma de estructurar la realidad que el psicoanálisis lacaniano denomina como el Nombre-del-Padre16. Una visión metafórica de sus pretensiones de poder a la que se han adaptado materiales tan representativos de este nuevo regeneracionismo como la Historia total de España (1997), de Ricardo de la Cierva; Al-Andalus contra España (2001), de Serafín Fanjul; De Hispania a España (2005), de Vicente Palacio Atard; o Imperiofobia y Leyenda negra (2016), de María Elvira Roca Barea.

Este retorno a la idea de nación como totalidad histórica, revitalizó a la misma minoría dirigente que insistía, ahora desde las instituciones democráticas, en la capacidad "homogeneizadora" del Estado español para afianzar su hegemonía, apelando a una nueva 'causa nacional' a la que, de alguna manera, también han sido convocados los estamentos comunitarios, tras impulsar la conversión del país en lo que Peter Andreas ha denominado como la "Fortaleza

\footnotetext{
${ }^{16}$ Concebir el país de esta manera, implicaba otorgar a las narrativas y afectos nacionales el papel de la Ley, es decir; del "significante que representa la autoridad y el orden instituyente" (Stavrakakis, 2010: 201). Es por eso que, en este contexto, el Estado-nación termina por equipararse con la figura metafórica del padre, en la medida en que, son sus estructuras las que marcan de forma preferente el proceso colectivo de socialización con "el deseo y la falta" (Homer, 2016: 72).
} 
de Europa" (2000:127). Aunque este eufemismo no ha hecho sino exacerbar el papel accesorio de España y de la mayoría de los Estados del Sur del continente, a pesar de su participación en el Espacio Schengen (1995), la adopción del Euro (1999), la firma de los tratados de Ámsterdam (1999), Niza (2003) y Lisboa (2009), así como el aumento exponencial de las labores de vigilancia y control de sus fronteras, ejercida a través de una calculada política de acción exterior, cooperación internacional y persecución del narcotráfico, que también incluiría, tras el 11-S (2001), la Guerra de Irak (2003-2004) y el 11-M (2004), la lucha contra el terrorismo global.

Como resultado de este proceso, muchos de los territorios de la Europa meridional han trocado su funcionalidad como "salas de espera" para los grandes flujos migratorios por el de "países receptores" de inmigración (Cachón, 2002:98), un proceso que ha adquirido un creciente "protagonismo en la vida social y en el imaginario" de dichas naciones, por más que haya sido una sola de sus modalidades la que ha acaparado casi todo su interés: la "inmigración no comunitaria" (Santamaría, 2002:104). Hablo de un fenómeno que, si ha recibido la catalogación de "ilegal", a pesar de los vínculos históricos del continente con el colonialismo, ha sido para forzar la conversión de sus protagonistas, en su gran mayoría "viejos conocidos" de estas antiguas metrópolis, en "extraños" visitantes (Estévez, 2016: 168) en el espacio en que se impone el Nuevo Orden Económico Mundial.

Así ha sucedido, desde luego, con las 'herencias' que el nacionalismo español ha revitalizado en plena colonialidad global, resultando especialmente recurrentes los sesgos clase, raza, género y episteme con los que aún es investida su otredad. De hecho, esta alteridad se ha convertido en todo un anatema al interior de las principales fantasías nacionalistas del hispanismo posmoderno, sobre todo en los casos de comunidades poscoloniales tan representativas como la musulmana, la gitana, la latinoamericana o la subsahariana. Aunque es cierto que, como parte de esta monomanía subalternizadora, la "diferencia imperial-interna" (Mignolo, 2003: 43) ha cumplido con su acostumbrado papel, ya no sólo a la hora de instrumentalizar el eje de relaciones jerárquicas Norte-Sur que continúa operando entre los países que forman la Unión Europea, sino también a la hora de gestionar los disensos patrióticos que coexisten en España. Y, ello a pesar de la deliberada estrategia de visualización y consumo asumida por el Estado durante las dos últimas décadas, incluidos los años de alternancia progresista que supuso el gobierno de José Luis Rodríguez Zapatero (2004-2011), igualmente empeñado, si bien con matices, en presentar a España como resultado de una visión unitaria de su "normalidad nacional" (Davis, 1995: 29)17.

\footnotetext{
17 El "imperialismo cultural" se sostiene en "el poder de universalizar los particularismos ligados a una tradición histórica singular" hasta tal punto, que estos terminan por "no reconocerse como tales" (Bourdieu y Wacquant, 1999: 41). Como lo asevera Luisa Elena Delgado, "la única forma en que la universalidad española" ha podido "existir", ha sido "bajo la apariencia de su opuesto, de lo que parece un exceso 'nacionalista', irracional e inmotivado" (2014: 83). Este antagonismo, sin embargo, no ha resultado ser uniforme ni tampoco demasiado exitoso, a pesar de haber sido utilizado recurrentemente por los sucesivos gobiernos de España desde la Transición.
} 


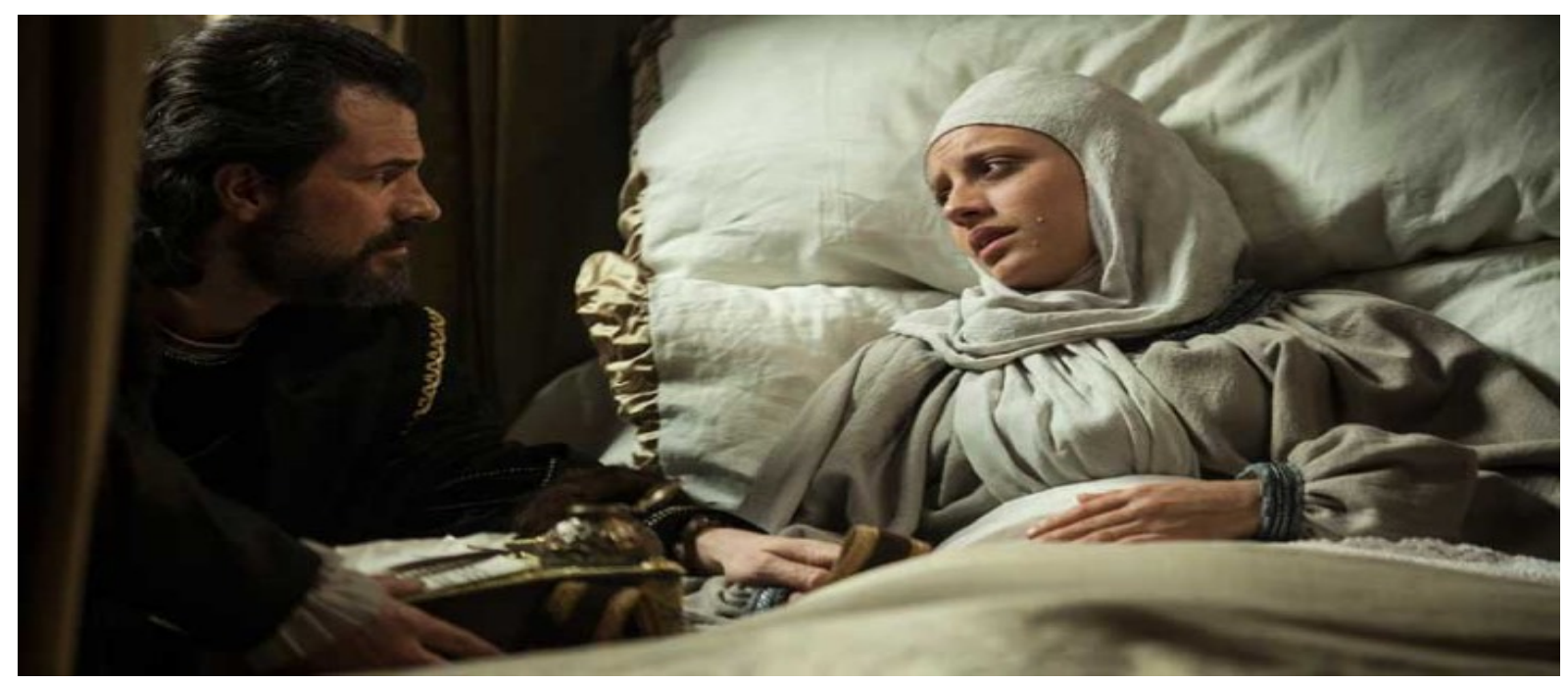

Ilustración no 4. "Nada de cuanto hemos logrado juntos se perderá, os lo juro. Pues velando por vuestros logros, guardaré memoria del inmenso amor que siempre he sentido por vos" (Frades, 2014: 1:10:34-48). Con estas palabras, la serie Isabel (Cap. 39, 2014), emitida por Televisión Española durante el peor momento de la crisis que recientemente ha asolado al país, recrea la despedida que Fernando II de Aragón (interpretado por Rodolfo Sancho) le dedicó a Isabel I de Castilla (encarnada por Michelle Jenner) en su lecho de muerte. Llegaba a su término una trama marcada por las intrigas propias del ejercicio del poder, convenientemente estimuladas por un insistente refuerzo afectivo decidido a 'sentimentalizar' la biografía de sus personajes. El programa alcanzaba así su punto álgido, eligiendo como cierre una 'declaración de amor' que en su peculiaridad abrigaba una auténtica promesa de plenitud, llamada a trascender el plano afectivo en que ha sido formulada para inscribirse, sin lugar a dudas, en un espacio que es histórico y sobre todo político. Se trataba, en efecto, de un juramento capaz de equiparar la íntima biografía del 'padre y la madre fundadora' del hispanismo moderno con su problemática posmodernidad con el cometido de cumplir el fin último de todo nacionalismo: convocar en un mismo escenario narrativo a la pasión y la ideología.

En este sentido, tiene razón Susan Martin-Márquez cuando asegura que, "el debate identitario sobre el pasado" de España y las disquisiciones sobre la significación actual de lo español, no han hecho otra cosa que "intensificarse" (2011: 354) desde el inicio del siglo XXI. Es más, en los últimos años, numerosas discusiones sobre sus afectos y retóricas compartidas han determinado el alcance de esa obstinada postulación fantasmática sobre lo que constituye y lo que no su corpus nacional, tantas veces articulado a través de una serie de categorías que, han resultado más o menos litigantes en la medida en que sus protagonistas han sido capaces de escenificar para su sociedad un riesgo real de robo del goce $e^{18}$. Y, esta condición, persistentemente ambigua, también ha incidido en la repetición de los mismos estereotipos esencialistas que han definido la corpo-política que el Estado español todavía aplica, no sólo a su población extranjera, sino también a una porción importante de sus 'naturales'. Concretamente, a la parte que ha sido declarada como 'adversaria de la patria' por el mero hecho de cuestionar su "verticalidad, desproblematización” y violencias a la hora de procurar su "cohesión” (Martínez, 2012: 20), por más que dichas pretensiones hayan incrementado la debilidad del país a partir del giro neoliberal,

18 "Lo que da consistencia a la construcción discursiva de la nación es el fantasma que promete nuestro encuentro con la plenitud del goce situado/proyectado en las raíces de la historia nacional". Mientras que, "la idea de que otra persona [el Otro nacional] ha sustraído nuestro goce" sirve para preservar «nuestra fe en la existencia del goce perdido y en la posibilidad de recuperarlo" mediante su "realización plena en el futuro, cuando logremos recobrarlo del Otro que nos lo ha robado" (Stavrakakis, 2010: 223, 225). 
neocolonialista y otra vez casticista experimentado mientras presidió su gobierno el conservador Mariano Rajoy Brey (2011-2018) y, de nuevo con ciertos matices, el progresista Pedro Sánchez (2018- ).

Está por ver, no obstante, si esta sintomatología social ha servido para evidenciar un malestar tan grande como para empezar a hablar del final de la España de la Transición, por mucho que apunten en esa dirección sucesos en curso como, por ejemplo, el aumento exponencial de los casos judicializados de corrupción política (2007- ), la gran recesión económica y financiera que ha asolado al país (2008- ), el Procés independentista iniciado en Cataluña (2010- ), así como las demandas democráticas expresadas por el Movimiento 15-M (2011) o el fin del bipartidismo (2015- ). En cualquier caso, este conjunto de fenómenos sociológicos lo que sí han evidenciado hasta el momento es la revelación de un rosario de pulsiones que ya han dejado de pertenecer, exclusivamente, al terreno de su inconsciente nacional 1 .

\section{A MODO DE CONCLUSIÓN}

Si damos por seguro que la identidad se logra mediante la "inscripción de fronteras" que permiten la explicitación de unos "Otros" que "Nosotros" no somos (Campbell, 1998:9). ¿Cómo ir más allá de ese reduccionismo? ¿Cómo dejar atrás la fantasía moderna/posmoderna que ha encubierto insistentemente el rostro colonial/poscolonial de España?

Jaqueline Rose acierta al afirmar que, para «atravesar la fantasía» que toda identidad representa, debemos asumir "una nueva posición en relación al Otro, su lenguaje y su deseo" (en Delgado, 2014: 96), una posición en la que es necesario asumir que nuestra identidad también comprende aquello que nos falta. Esto es, cuanto forma parte de nuestra otredad constitutiva, aun cuando hablamos de identidades que pretenden detentar la hegemonía y presentarse, no sin resistencias, bajo la forma de una totalidad universal, como ha sido el caso de España durante los últimos seiscientos años.

Para tratar de reproducir dicha mecánica he redactado este análisis provisorio, ordenado en torno a cuatro grandes oleadas de exaltación de una identidad que ha dado muestras suficientes de su contingencia. Cuatro momentos a través de los que he intentado volver inteligible la naturaleza ontológica de cuanto ha conformado lo español, entendido como resultado de la circulación de significantes llamados a encarnar las distintas modalidades de goce que han organizado sus más representativas "prácticas sociales" y "mitos nacionales" (Žižek, 1993: 202). Eso sí, reclamando en todo momento la condición subalterna de los numerosos elementos que han sido relegados en dicho ejercicio a las perturbadoras regiones de la colonialidad, y que, aún se resisten a ocupar tales posiciones, demandando la apertura de escenarios en los que dar cabida a

\footnotetext{
$19 \mathrm{El} \mathrm{"inconsciente} \mathrm{consiste} \mathrm{en} \mathrm{material} \mathrm{significante"} \mathrm{y} \mathrm{es} \mathrm{resultado} \mathrm{de} \mathrm{"un} \mathrm{proceso} \mathrm{de} \mathrm{significación} \mathrm{que} \mathrm{se} \mathrm{encuentra}$ más allá de nuestro control: es el lenguaje que habla a través de nosotros, más que el lenguaje que nosotros hablamos". En este sentido, Lacan describe el "inconsciente como el discurso del Otro" (Homer, 2016: 65), lo que, al ser aplicado al contexto nacionalista, extendería los límites de la identidad hasta abarcar a una comunidad que comparte determinadas fantasías, símbolos y apegos, en síntesis: "lo distintivo que nos hace gozar lo que los otros no tienen" (Keohane. 1992: 20).
} 
esas "otras historias y otras voces disonantes, incluso disidentes" (Bhabha, 2002: 21) que también han formado parte de su autorretrato.

Ahora que en España se vuelven a vivir tiempos de crisis, se abre una nueva oportunidad para adaptar sus genealogías a los nuevos márgenes gnoseológicos que propone el pensamiento descolonial a través de la formulación de un "conocimiento otro" (C. Walsh, 2007:47). Es decir, de una nueva fórmula identitaria que al "olvidar, y así recordar ciertos eventos de una manera particular" (Krauel, 2013: 3), puede ser consciente de los límites simbólicos y emocionales que han afectado a sus principales estructuras de saber y del ser a lo largo del tiempo. Ahora bien, esta novedosa reflexividad también debe procurar, como punto de partida, no desmentir las exclusiones provocadas por sus blanqueadas jerarquías de carácter epistémico, racial, de género y de clase, para que así, donde hoy se impone la oscuridad, puedan emerger espacios nuevos de auto-representación.

En definitiva, mis esfuerzos se han dirigido a estimular el acto inaplazable de la descolonización de la economía totalizante que ha revestido al españolismo a lo largo de su historia (pos)moderna y (pos)colonial, decidida a dislocar sus formas normalizadas para dar entrada a lo que Luisa Elena Delgado ha denominado como "la parte sin parte" (2015:28) de su identidad nacional. En este caso, entendida como esa porción de lo hispano cuya negación ha supuesto, paradójicamente, su forma más primaria de reconocimiento, por más que sus respectivos "fragmentos" no hayan podido ser aún simbolizados, por mucho que estos vivifiquen todavía el lado oscuro de la nación. 
BIBLIOGRAFÍA

Abulafia, David (2009). El descubrimiento de la Humanidad: encuentros atlánticos en la era de Colón. Barcelona: Crítica.

Alfonso X, Rey de Castilla (1977) [1284] Primera crónica general de España. MenÉndez Pidal, Ramón (ed.). Madrid: Gredos.

Álvarez Chillida, Gonzalo (2009) [2002]. El Antisemitismo en España. La imagen del judío (1812-2002). Madrid: Ediciones de Historia.

ÁlvareZ JunCO, José (2001). Mater Dolorosa: la idea de España en el siglo XIX. Madrid: Taurus.

Álvarez Junco, José, De La Fuente, Gregorio (2017). El relato nacional. Historia de la historia de España. Madrid: Taurus.

Anderson, Benedict (2007) [1983]. Comunidades imaginadas. Reflexiones sobre el origen y la difusión del nacionalismo. México: Fondo de Cultura Económica.

Andreas, Peter (2000). Border Games: Policing the U.S.-Mexico Divide. Ithaca: Cornell University Press.

ANÓNIMO (2011) [1200]. Cantar del Mio Cid. Barcelona: Círculo de Lectores: Galaxia Gutenberg.

Appadurai, Arjun (1996). "Patriotism and Its Futures". Modernity at Large: Cultural Dimensions of Globalization. Minneapolis, Londres: University of Minnesota Press: 158-177.

Aranzadi, Juan. "Raza, linaje, familia y casa-solar en el País Vasco". Hispania 209 (2001): 879-906.

Aranzadi y UnAmuno, Telesforo de (1889). El Pueblo de euskalduna: estudio de antropología. San Sebastián: Diputación Provincial de Guipúzcoa.

ASTOR, Avi y GrIERA, Mar (2016). "La gestión de la diversidad religiosa en la España contemporánea". Anuario CIDOB de la inmigración: 248-270.

Aznar, Eduardo; Corbella, Dolores; Pico, Berta; Tejera, Antonio et al. (2006). Le Canarien: Retrato de dos mundos 1 y 2. La Laguna: Instituto de Estudios Canarios.

BERLANT, Lauren (2011) [2007]. El corazón de la nación. Ensayos sobre política y sentimentalismo. México: Fondo de Cultura Económica.

BHABHA, Homi K (2002) [1994]. El lugar de la cultura. Buenos Aires: Ediciones Manantial.

Bourdieu, Pierre, Wacquant, Loïc. "On the Cunning of Imterialist Reason". Theory, Culture and Society 16 (1999): 41-58.

FINK, Bruce (1997). A Clinical Introduction to Lacaninan Psychoanalysis: Theory and Technique. Cambridge: Harvard University Press.

CACHÓN RODRÍGUEZ, Lorenzo. "La formación de la «España inmigrante»: mercado y ciudadanía”. Reis: Revista Española de Investigaciones Sociológicas 97 (2002): 95-126. 
Campany y Montpalau, Antony de (1808). Centinela contra franceses. Valencia: Imprenta de Monfor.

CAmpany y MontPalau, Antony de (1786). Teatro bistórico-crítico de la elocuencia española. Madrid: Antonio de Sacha.

Campbell, David (1998). Writing Security: United States Foreing Policy and the Politics of Identity. Minneapolis: University of Minnesota Press.

CAStro-Gómez, Santiago (2005). La poscolonialidad explicada a los niños. Colombia: Editorial Universidad del Cauca.

CASTRO-GÓmEZ, Santiago. "Michel Foucault: colonialismo y geopolítica”. RODRíGUEZ, Ileana y MARTÍNeZ GutiÉrREZ, Mo José, et al. (2010). Estudios transatlánticos postcoloniales 1. Narrativas commando / sistemas mundos: colonialidad/modernidad. México: Anthropos Editorial: 271-292.

Cierva, Ricardo de la (1997). Historia Total de España. Del hombre de Altamira al rey Juan Carlos. Lecciones amenas de historia profunda. Toledo: Editorial Fénix.

Colón, Cristóbal (1991) [1492-1503]. Diario de a bordo. Madrid: Edición de Luis Arranz.

CONSTITUCIÓN POLÍTICA DE LA MONARQuía ESPAÑOLA (1812). Promulgada en Cádiz el 19 de marzo de 1812. Cádiz: Imprenta Real.

Costa, Joaquín (1906) [1884]. Los intereses de España en Marruecos son armónicos. Suplemento al número 9 de la Revista España en África, correspondiente al 15 de enero de 1906. MadridBarcelona: Imprenta de España en África.

Cruz, Jacqueline. "Of Good Torturers and Evil Workers: Antonio Munoz Molina's Plenilunio". Merino, Eloy E, Song, H. Rosi (2005). Traces of Contamination: Unearthing the Francoist Legacy in Contemporary Spanish Culture. Lewisburg: Bucknell University Press: 199-219.

DAVIS, Lennard J. (1995). "Nationalism and Deafness: The Nineteenth Century". Enforcing Normalcy: Disability, Deafness, and the Body. Londres: Verso.

De Las Casas, Bartolomé (1982) [1552]. Brevísima relación de la destrucción de las Indias. Madrid: Cátedra.

De PAZ-SÁncheZ, Manuel. "Identidades lejanas. El proyecto nacional canario en América (1895-1933)”. TZINTZUN. Revista de Estudios Históricos 46 (2007): 167-214.

Delgado, Luisa Elena (2014). La nación singular. Fantasías de la normalidad democrática española (1996-2011). Madrid: Siglo XXI.

DíAz Del CASTILlO, Bernal (2001) [1568]. Historia verdadera de la conquista de la Nueva España. Madrid: RAE.

DOR, Joél (1988). Estructura y perversiones. Buenos Aires: Gedisa.

Dussel, Enrique (1992). El encubrimiento del Otro. Hacia el origen del "mito de la Modernidad". La Paz: Plural Editores. 
Dussel, Enrique. "Europa, modernidad y eurocentrismo". LANDER, Edgardo [comp.] (1993). La colonialidad del saber: eurocentrismo y ciencias sociales. Perspectivas latinoamericanas. Buenos Aires: CLACSO.

Dussel, Enrique. "Más allá del eurocentrismo: El sistema-mundo y los límites de la modernidad”. CAstro-Gómez, Santiago, Guardiola-Rivera, Oscar, Millán de Benavides, Carmen (eds.) (1999). Pensar (en) los intersticios. Teoría y práctica de la crítica poscolonial. Bogotá: CEJA.

EANES DA Zurara, Gómez. "Crónica del descubrimiento y la conquista de Guinea". Boccaccio, Giovanni, DA'CA DA Mosto, Alvise et al. (1998). De Canaria y de las otras islas nuevamente halladas en el océano allende España. La Orotava: Ayuntamiento del Puerto de la Cruz y Ayuntamiento de la Villa de la Orotava.

Escobar, Arturo (1996). Más allá del Tercer Mundo: globalidad imperial, colonialidad global y movimientos antiglobalización. Bogotá: Nómadas.

Estévez GONZÁLEZ, Fernando. "Determinar la raza, imaginar la nación. El paradigma raciológico en la obra de Chil y Naranjo”. El Museo Canario LVI (2001): 329-346.

Estévez Hernández, Pablo (2016). El cuerpo de la Nación. Diferencia colonial y ausencia étnica en el censo español. La Laguna: Servicio de Publicaciones de la Universidad de La Laguna.

Falange Española (1933). Puntos Iniciales. Número 1. Semanario F. E. Madrid: 7 de diciembre de 1933.

FANJUL, Serafín (2001). Al-Andalus contra España: la forja del mito. Madrid: Siglo XXI.

FERNÁNDEZ DE OVIEDO, Gonzalo (1992) [1526]. Sumario de la natural y general historia de las Indias. Madrid: Confederación Española de Gremios y Asociaciones de Libreros.

Foucault, Michel (2007) [2004]. Nacimiento de la biopolítica. Curso en el Collège de France (1978-1979). Buenos Aires: Fondo de Cultura Económica.

FOX, Iman (1997). La invención de España. Nacionalismo liberal e identidad nacional. Madrid: Catedra.

Frades, Jordi (2012- 2014). Isabel. Guión de CALAFí, Jordi; DE BABEL, Isla; Olivares, Javier; SCHAAfF, Anaïs y Olivares, Pablo. España: Televisión Española y Diagonal TV.

FranÇA, José-Augusto. “Autorretrato como película”. Millares SAll, Manolo (2003). Luto de Oriente y Occidente. Dirección general de Relaciones Culturales y Científicas. Sociedad Estatal para la Acción Cultural Exterior, SEACEX: 131-133.

Franco, Francisco (1936). Proclama del Alzamiento. 18 de julio de 1936.

Friedman, Jerome (1987). "Jewish Conversion, the Spanish Pure Blood Laws and Reformation: A Revisionist View of Racial and Religious Antisemitism". Sixteenth-Century Journal 18 (1) (1987): 3-30.

GABILONDO, Joseba (2009). "Genealogía de la "raza latina": para una teoría atlántica de las estructuras raciales hispanas”. Revista Iberoamericana Vol. LXXV 228(2009): 795-818. 
Gener I BABOt, Pompeu (1887). Heregias: estudios de crítica inductiva sobre asuntos españoles. Barcelona: Fernando Fé.

GiL BenumeyA, Rodolfo (1952). Hispanidad y arabidad. España: Ediciones de Cultura Hispánica.

GISPERT, Carles y PRATS, Josep María (1978). España, un Estado plurinacional. Barcelona: Blume.

GramsCI, Antonio (2007) [1970]. Antología. México: Siglo XXI Editores.

Grosfoguel, Ramón. “La descolonización de la economía política y los estudios postcoloniales. Transmodernidad, pensamiento fronterizo y colonialidad global”. Tabula Rasa 4 (2006): $17-48$.

GRÜNER, Eduardo (2012). "El sistema-mundo, América colonial y la esclavitud afroamericana". La oscuridady las luces. Capitalismo, cultura y revolución. Buenos Aires: Edhas: 147-214.

Homer, Sean (2016) [2005]. Jacques Lacan. Una introducción. Madrid: Plaza y Valdés Editores.

Juliá, Santos (1998). "Retóricas de muerte y resurrección: los intelectuales en la crisis de conciencia nacional”. Debates en torno al 98: Estado, Sociedad y Política. Madrid: Comunidad de Madrid Consejería de Educación y Cultura Secretaría General Técnica: 159-170.

KeOHANE, Kieran. "Symptoms of Canada: National Ideology an the Theft of National Enjoyment". Cine ACTION 28 (1992): 20-33.

KRAUEL, Javier (2013). Imperial Emotions. Cultural Responses to Myths of Empire in Fin-de-Siècle Spain. Liverpool: Liverpool University Press.

LACLAU, Ernest y MOUFFe, Chantal (2004). Hegemonía y estrategia socialista. Hacia una radicalización de la democracia. Buenos Aires: Fondo de Cultura Económica.

Lipovetsky, Gilles (2000). El crepúsculo del deber. La ética indolora de los nuevos tiempos democráticos. Barcelona: Anagrama.

LugOnES, María. “Colonialidad y género”. Tábula Rassa 9 (2008): 73-101.

Madariaga, María Rosa de. "En torno a al-Andalus: extrapolaciones históricas y utilizaciones abusivas”. Fernández PARrilla, Gonzalo, Feria García, Manuel C. (2000). Orientalismo, exotismo y traducción. Cuenca: Ediciones de la Universidad de Castilla-La Mancha: 81-89.

MAldonAdo-TORRes, Nelson. "Aimé Césaire y la crisis del hombre europeo". CÉSAIRE, Aimé (2006). Discurso sobre el colonialismo. Madrid: Akal: 173-196.

MANNHEIM, Karl (2004) [1936]. Ideología y Utopía. Introducción a la sociología del conocimiento. México: Fondo de Cultura Económica.

MARTÍNEZ, Guillem. "El concepto CT". MARTínEZ, Guillem et al. (2012). CT o la Cultura de la Transición. Crítica a 35 años de cultura española. Barcelona: Debolsillo: 13-23.

MArTín-MÁrquez, Susan (2011) [2008]. Desorientaciones. El colonialismo español en África y la performance de identidad. Barcelona: Edicions Bellaterra.

MezILAS, Glodel (2015). El Trauma Colonial entre la Memoria y el Discurso. Pensar (desde) el Caribe. Florida: Educa Visión Inc. 
MignOLO, Walter (2003) [2001]. Historias locales; diseños globales: Colonialidad, conocimientos subalternos y pensamiento fronterizo. Madrid: Akal.

Mignolo, Walter (2010). Desobediencia epistémica: Retórica de la modernidad, lógica de la colonialidad, gramática de la descolonialidad. Buenos Aires: Ediciones del Signo.

Millares Sall, Manolo (1959). El Homúnculo. Técnica mixta sobre arpillera. 162,5 x 130,5 cm. Colección privada, Navarra.

Morales Lezcano, Víctor (1988). Africanismo y orientalismo español en el siglo XIX. Madrid: UNED.

Murguía, Manuel (1865). Historia de Galicia Tomo 1. Lugo: Imprenta de Soto Freire.

Negri, Antonio y HARDT, Michael (2009). Imperio. Barcelona: Paidós.

NERÍN, Gustau (1998). Guinea Ecuatorial: historia en blanco y negro (1843-1968). Barcelona: Península.

Nerín, Gustau (2005). La guerra que vino de África. Barcelona: Crítica.

Nobus, Dany (2000). Jacques Lacan and the Freudian Practice of Psychoanalysis. Londres: Routledge.

Nordau, Max (2004) [1892]. Degeneración. Pamplona: Analecta.

O’Gorman, Edmundo (1958). La invención de América: el universalismo de la cultura de occidente. México: Fondo de Cultura Económica.

OlÓRIZ Aguilera, Federico (1894). Distribución geográfica del indice cefálico en España deducida del examen de 8.368 varones adultos. Madrid: Memorial de Ingenieros.

ORTEGa y GASSET, José (1921). La España invertebrada. Bosquejo de algunos pensamientos históricos. Madrid: Calpe.

Palacio Atard, Vicente (2005). De Hispania a España: El nombre y el concepto a través de los siglos. Madrid: Temas de Hoy.

Pedrós-Gascón, Antonio Francisco. "Héroes para un nuevo 98 (Acerca de una invisibilidad ideológica en la novela española reciente)”. España contemporánea: Revista de literatura y cultura 1 (2009): 7-34.

Perceval, Jose María (1997). Todos son uno: arquetipos, xenofobia y racismo: La imagen del morisco en la Monarquía Española durante los siglos XVI y XVII. Almería: Instituto de Estudios Almerienses.

Prat Carós, Joan, Martínez, Ubaldo, Contreras, Jesús, Moreno, Isidoro (1991). Antropología de los Pueblos de España. Madrid: Taurus.

PupO-WALKer, Enrique (1982). La vocación literaria del pensamiento bistórico en América. Desarrollo de la prosa de ficción: siglos XVI, XVII, XVIII y XIX. Madrid: Gredos.

QuijAnO, Aníbal (2014). "Colonialidad del poder y clasificación social”. Cuestiones y horizontes: de la dependencia histórico-estructural a la colonialidad/descolonialidad del poder. Buenos Aires: CLACSO: 285-327.

RAMA, Carlos M. (1982). Historia de las relaciones culturales entre España y la América Latina. Siglo XIX. México: Fondo de Cultura Económica. 
RAmsden, Herbert (1967). Angel Ganivet's Idearium español: A Critical Study. Manchester: Manchester Univeristy Press.

RANCIÈRE, Jacques (2012) [1996]. El desacuerdo. Politica y filosofía. Buenos Aires: Ediciones Nueva Visión.

ReAle, Giovanni, ANTISERI, Dario (1998). Historia del pensamiento filosófico y cientifico. Tomo III. Del romanticismo hasta hoy. Barcelona: Editorial Herder.

RiviÈre GÓMEZ, Aurora (2000). "Orientalismo y nacionalismo español: estudios árabes y hebreos en la Universidad de Madrid(1943-1868). Madrid: Editorial Dykison.

Morillo Caballero, Manuel (ed.) (2005). Romancero viejo. Madrid: Isla del Gallo.

ROSALDO, Renato (2000). Cultura y verdad. La reconstrucción del análisis social. Quito: ABYA-YALA.

SAID, Edward (2007) [1978]. Orientalismo. Barcelona: Random House.

SANTAMARÍA, Enrique (2002) La incógnita del extraño. Una aproximación a la significación sociológica de la "inmigración no comunitaria". Barcelona: Anthropos.

SCHMIDT-NOWARA, Christopher. "Introduction: Intrepreting Spanish Colonialism". SCHMIDTNOWARA, Christopher, NieTO-Phillips, John M. [eds.] (2005). Interpreting Spanish Colonialism: Empires, Nations and Legends. Albuquerque: University of New Mexico Press.

SEPúlvedA, Ginés de (1941) [1550]. Tratado sobre las justas causas de la guerra contra los indios. México: Fondo de Cultura Económica.

SHAW, Jo (2000). "The "Governance" Research Agenda and the "Constitutional Question". Governance and Citizenship in Europe: Some Research Questions. Luxemburgo: European Communities: 70-81.

SPIVAK, Guayatri Chakravorty. “¿Puede hablar el subalterno?”. Revista Colombiana de Antropología 39 (2003): 297-364.

SPIVAK, Guayatri Chakravorty (2010). Crítica de la razón poscolonial. Hacia una historia del presente evanescente. Madrid: Akal.

STALlAERT, Christiane (1998). Etnogénesis y etnicidad en España. Una aproximación bistóricoantropológica al casticismo. Barcelona: Proyecto A Ediciones.

Stanislas Adotevi, Spero (2004). "La diversité culturelle aujourd'hui". Diversité culturelle et mondialisation. París: Editions Autrement: 59-79.

STOCKING, George W. (1985) [1982]. Race, culture ande evolution: Essays in the History of Anthropology, with a new preface. Chicago: London University of Chicago Press.

Stavrakakis, Yannis (2010) [2007]. La iqquierda lacaniana. Psicoanálisis, teoría, política. México: Fondo de Cultura Económica.

SubIRATS, Eduardo (1994). El Continente vacío. La conquista del Nuevo Mundo y la conciencia moderna. Barcelona: Anaya y Mario Muchnik. 
TORRES, Max S. Hering. "La limpieza de sangre. Problemas de interpretación: acercamientos históricos y metodológicos". Historia Critica 45 (2011): 32-55.

TOulmin, Stephen Edelston (1990). Cosmópolis: el trasfondo de la modernidad. Presentación de José Enríquez Ruiz-Domènec. Traducción de Bernardo Moreno Carrillo. Barcelona: Ediciones Península.

TOYNBEE, Arnold J. (1987). Estudio de la historia. Madrid: Alianza.

VÁZQUEZ GARCÍA, Francisco (2009). La invención del racismo: nacimiento de la biopolitica en España, 1600-1940. Madrid: Akal.

Vitoria, Francisco de (1989) [1539]. Relectio de Indis. Carta Magna de los indios. Madrid: Consejo Superior de Investigaciones Científicas.

WALSH, Catherine. "Interculturalidad y colonialidad del poder. Un pensamiento y posicionamiento "otro" desde la diferencia colonial". CASTRO-GÓMEZ, Santiago y Grosfoguel, Ramón (eds.) (2007). El giro decolonial. Reflexiones para una diversidad epistémica más allá del capitalismo global. Bogotá: El siglo del hombre Editores.

ŽIŽEK, Slavoj (1993) Tarrying with the Negative, Kant, Hegel and the Critique of Ideology. Durham: Duke University Press.

ŽIŽEK, Slavoj (2010) [2006]. Cómo leer a Lacan. Buenos Aires: Paidós.

Zorrilla, José (1847). Obras Poéticas de D. José Zorrilla. París: Librería Europea. 